indumento calicinal y su coloración, blanca o amarilla; forma de los capitulos florales , suboblongos o espiciformes; crenación de los márgenes foliares.y color de la corola, blanca o rosada.

Este taxon del Marruecos occidental presenta una similaridad morfológica muy acentuada (Maire,1938) con otras poblaciones del Norte de Marruecos y de la región del Rif, de corología y ecologías próximas a las de T. murcicum en el sureste de la Península Ibérica y que aparecen identificadas de forma puntual sobre material de herbario por autores clásicos españoles(Sennen, F. 1928-1930. Plantes D’Espagne et du Maroc.) como: T. maroccanum Sennen nom. illeg. y posteriormente revisadas por Sauvage \& Vindt, 1955 como: T. capitatum var. capitatum sub. var. capitatum $(T$. capitatum f.Lazari Sennen); T. capitatum var. corymbiferum sub. var. rufanum (T. maroccanum Sennen) o sub. var. humberti Maire \& Sennen. Un estudio biosistemático detallado de estos táxones, a través de su área de distribución, como el que se está realizando actualmente nos permitirá su actualización sistemática y pondría de manifiesto sus relaciones taxonómicas y biológicas, entre sí y con T. murcicum del sureste de la Península Ibérica y de las Islas Baleares.

\title{
BIBLIOGRAFÍA
}

SAUVAGE, CH \& J. VINDT. -1955- Synopsis du genre Teucrium sct, Polium au Maroc. Bull. Soc. Nat. Phys. Maroc, 35(4):283-293.

SAUVAGE, CH \& J. VINDT. -1967-Revisión del Herbier de Linstitut Scientifique Chérifien. Notes Critiques. Le Botaniste serie L, 515-436.

MAIRE, R. -1938-Contribution à l'étude de la Flore de l'Afrique du Nord . Bull. Soc. Hist. Nat. Afr. Nord., 29: 445 (1938).

NAVARRO, T , J. L. ROSUA y J. F. MOTA. -1990- Estudio sistemático de los táxones de la Serie Polium, genéro Teucrium L., en las Cordilleras Béticas. Acta Botánica Malacitana, 15:79-91.

(Aceptado para su publicación en septiembre de 1991)

Dirección de los autores: (1): Departamento de Biología Vegetal. Facultad de Ciencias. Univeridad de Málaga. 29080 Málaga. (2): Departamento de Biología Vegetal. Facultad de Ciencias. Universidad de Granada. 18001 Granada.

\section{NOTAS BIOGEOGRÁFICAS Y ECOLÓGICAS SOBRE ALGUNOS TAXONES LITORALES DEL GÉNERO TEUCRIUM L. (LAMIACEAE) EN ANDALUCÍA}

Palabras clave. Teucrium, ecología, Andalucía, España.

Teresa NAVARRO, José Luis ROSÚA y José Ma․ NIETO CALDERA

Los táxones del género Teucrium L., de distribución mediterránea, y cuya corología en la Península Ibérica queda limitada exclusivamente a la banda costera del 
litoral andaluz, son: $T$. polium subsp. vicentinum y $T$. campanulatum en las costas atlánticas; $T$. polium subsp. rupestricolum y $T$. intricatum para las costas de facies mediterránea y $T$. dunense en todo el litoral de Andalucía.

Teucrium polium subsp. rupestricolum (Sennen) Navarro y Rosúa Candollea 45: 582.1989.

=T. polium var. rupestricolum Sennen, Diagn. Nouv.: 150. 1936.

Corología: Provincia Bética (sectores Malacitano-Almijarense y AlpujarroGadorense) y Murciano-almeriense (sector Almeriense). Sustituye en el litoral mediterráneo andaluz al T. polium subsp. vicentinum y se distribuye de forma discreta en la banda costera de Málaga, Granada y Almería. En el norte de Almería y Murcia, el número de poblaciones disminuye siendo remplazado por T. lanigerum de la Serie Simplicipilosa y más tarde en el litoral alicantino por el $T$. homotrichum de la serie Polium.

Ecología: Vive en acantilados y cantiles sublitorales. Es indiferente edáfico, crece directamente sobre la roca madre o en pequeñas repisas con algo de suelo. $\mathrm{Su}$ avance hacia el interior, escaso, se hace a través de barrancos o ramblas de las estribaciones de sierras litorales. Aparece en acantilados esquistosos de las costas bajas con playas de cantos rodados desde Cala del Moral y Punta de Torrox (Málaga) hasta Adra (Almería), conviviendo en ocasiones con el fisurícola T fragile. En la bahía de Almería, vive en acantilados carbonatados con T. intricatum. A partir de Cabo de Gata, vive en cantiles de andesitas, margas y calcarenitas, cohabitando con T. charidemi, desde Carboneras, en los acantilados de metamórficas y margas, es remplazado por $T$. lanigerum, hasta el litoral murciano donde se sustituye por T. carthaginense.

Presenta una clara adaptación morfológica a la maresía: caméfito almohadillado, denso indumento que cubre la planta y las inflorescencias concentradas en un capítulo único terminal. Las variaciones morfológicas más patentes son relativas a la coloración del indumento, verde, gris o amarillento, y a los verticilos foliares: trímeros en los sectores Malacitano-Almijarense y Alpujarro-Gadorense y dímeros en el Almeriense.

Fitosociología: Aparece en comunidades de Crithmo-Limonietea Br.-B1. 1947, Asplenietea trichomanis (Br.-Bl. in Meier \& Br.-Bl. 1934) Oberdorfer 1977 (Asplenietalia glandulosi Meier \& Br.-Bl. nom mut.). También se encuentra en matorrales abiertos de las estribaciones costeras litorales de las sierras béticas, en Ononido-Rosmarinetea $\mathrm{Br}$--Bl. 1947 se encuentra en Helianthemo-Siderition pusillae Alcaráz et al. 1989 (Helianthemo almeriensis-Sideritetum pusillae Alcaráz et al. 1989) y en jarales de Cisto-Lavanduletea Br-B1. (1940) 1952, de suelos ligeramente básicos y no demasiados húmedos.

Teucrium intricatum Lange Vid. Meddel. Dansk. Naturh. Foren. Kjobenhaun 1863: 21 (1863)

Corología: Endemismo del sector Almeriense (provincia Murciano-Almeriense).

Ecología: Vive en acantilados y cantiles sublitorales de la Sierra de Gador penetra escasamente hacia el interior a través de ramblas térmicas.Especie fisurícola crece en grietas 
o repisas de roca madre caliza o dolomítica.

Fitosociología: Se desarrolla en comunidades de Asplenietea trichomanis (Br.-Bl. in Meier \& Br.-B1. 1934) Oberdorfer 1977 (Asplenietalia glandulosi Meier \& Br.-Bl. nom mut., Teucrion buxifolii Rivas Goday 1955, Galio ephedroidis-Phagnaletum saxatile Rivas Goday y Esteve 1972)

Teucrium campanulatum L. Sp. Pl. 562: 1753.

Corología: Representado puntualmente en la provincia Gaditano-Onubo-Algarviense (sector Gaditano).

Ecología: Vive sobre terrenos arcillosos generalmente encharcados o en suelos arenosos mal drenados.

Fitosociología: Aparece en comunidades de Cicendion (Rivas Goday (1961) 1964) Br.-Bl. 1967 (Isoeto-Nanojuncetea Br.-Bl. \& R. Tx. 1943, Isoetetalia Br.-Bl. 1931 ampl. Rivas Goday 1970).

Teucrium polium subsp. vicentinum (Rouy) Wood, Bot. J. Linn. Soc. 65: 261. 1972. $=T$. vicentinum Rouy, Le Naturaliste $2: 20.1882$. (basion.)

Corología: Provincia Gaditano-Onubo-Algarviense. Sur de Portugal y franja costera andaluza, siendo la bahía de Algeciras y el Peñón de Gibraltar sus limites orientales.

Ecología: Vive exclusivamente en las partes elevadas de los acantilados y roquedos calizos sometidos a fuerte maresía.

Fitosociología: Se desarrolla en comunidades de Crithmo-Limonietea Br.-Bl. 1947 (Crithmo-Limonietalia Molinier 1934, Crithmo-Daucion halophili Rivas-Martínez et al. 1987, Astragaletum vicentini Rivas-Martínez et al. 1987

Teucrium dunense Sennen, Pl. D‘Espagne № 53781925 (in Sched.)

Corología: Se distribuye discretamente a lo largo de todo el litoral andaluz (provincias Gaditano-Onubo-Algarviense, Bética y Murciano-Almeriense). Es frecuente en la franja litoral onubense y gaditana; desde Gibraltar hasta Málaga su distribución es puntual y a veces escasa o nula. Su presencia se intensifica considerablemente a partir del sector AlpujarroGadorense.

Ecología: Vive en dunas litorales en proceso de fijación por lo que es normal que aparezcan ciertos fanerófitos como acompañantes. En las dunas semifijas crece en vaguadas interdunares formando comunidades densas. También puede estar presente en comunidades de bordes de playas arenosas o de guijarros con cierta influencia nitrófila y en los bordes de salinas y lagunas litorales formando parte de los saladares. Presenta una adaptación morfológica completa al suelo arenoso; en la estructura de sistema radicular, su biotipo, las hojas semisuculentas y la coloración glauca de la epidermis. En las comunidades de saladares, los verticilos foliares pueden ser dímeros o trímeros y la distancia internodal se reduce.

Fitosociología: Aparece en comunidades de Ammophilletea Br.-Bl. \& R. Tx. 1943 (Ammophiletalia Br.-Bl.(1931) 1932, Crucianellion maritimae Rivas Goday y Rivas-Martínez 1963, Crucianellenion), en Cakiletea maritimae R. Tx. \& Preising in R. Tx. 1950 y Quercetea ilicis Br.-Bl. 1947 (Pistacio-Rhamnetalia alaterni Rivas-Martínez 1975, Juniperion lyciae Rivas-Martínez 1975, Rhamno-Juniperetum macrocarpae Rivas-Martínez 1964). También puede integrarse en la geoserie de los saladares (Arthrocnemetea Br.-Bl. \& R. Tx. $1943 \mathrm{em}$. 
O. Bolós 1957) y en jarales sobre dunas estabilizadas (Cisto lavanduletea Br-Bl. (1940) 1952, Lavanduletalia Br.-Bl. 1940 em Rivas-Martínez 1968, Stauracantho-Halimion Rivas-Martínez 1979, Halimio halimifolii-Stauracanthetum genistoidis Rivas-Martínez et al. 1980), tal y como se encuentra en las proximidades de Marbella. En Ononido-Rosmarinetea Br.-Bl. 1947 se encuentra en Helianthemo-Siderition pusillae Alcaráz et al. 1989 (Teucrio belionisHelianthemetum scopulorum Peinado et al. 1985).

(Aceptado para su publicación en septiembre de 1991)

Dirección de los autores: T. Navarro, J.M. Nieto \& B. Cabezudo: Departamento de Biología Vegetal. Facultad de Ciencias. Universidad de Málaga. J.L. Rosúa: Departamento de Biología Vegetal. Universidad de Granada. 